\title{
Model coupling in resource economics : conditions for effective interdisciplinary collaboration
}

\section{MacLeod, Miles Alexander James}

2016

MacLeod, M A J \& Nagatsu, M 2016 , ' Model coupling in resource economics : conditions for effective interdisciplinary collaboration ', Philosophy of Science, vol. 83 , no. 3 , pp. 412-433 . https://doi.org/10.1086/685745

http://hdl.handle.net/10138/228204

https://doi.org/10.1086/685745

publishedVersion

Downloaded from Helda, University of Helsinki institutional repository.

This is an electronic reprint of the original article.

This reprint may differ from the original in pagination and typographic detail.

Please cite the original version. 


\title{
Model Coupling in Resource Economics: Conditions for Effective Interdisciplinary Collaboration
}

\author{
Miles MacLeod and Michiru Nagatsu*
}

\begin{abstract}
In this article we argue for the importance of studying interdisciplinary collaborations by focusing on the role that good choice and design of model-building frameworks and strategies can play overcoming the inherent difficulties of collaborative research. We provide an empirical study of particular collaborations between economists and ecologists in resource economics. We discuss various features of how models are put together for interdisciplinary collaboration in these cases and show how the use of a coupled-model framework in this case to coordinate and combine background models from ecology and economics provided particular collaborative affordances and clear collaborative gain.
\end{abstract}

1. Introduction. Recent years have seen a burgeoning interest in promoting and analyzing interdisciplinary collaboration in the natural and social sciences by researchers and university administrators. There is now a substantial collection of academic work and policy documents available on the subject. Most interdisciplinarity research so far has been the domain of science policy and science and technology studies. This research has focused on the institutional, organizational, and social dimensions of scientific research that promote or inhibit interdisciplinary interactions while developing policy frameworks and guidelines for structuring scientific institutions and organization to promote interdisciplinary interactions (see, e.g., Gibbons et al. 1994). What is largely missing however is an actual case-based study of how the available cognitive resources of different scientific fields and disciplines - their extant theories, modeling templates, experimental and evi-

Received March 2015; revised October 2015.

*To contact the authors, please write to: Miles MacLeod, Cubicus Building, Dienerlolaan 5, Enschede 7522 NB, Netherlands; e-mail:m.a.j.macleod@utwente.nl.

Philosophy of Science, 83 (July 2016) pp. 412-433. 0031-8248/2016/8303-0006\$10.00

Copyright 2016 by the Philosophy of Science Association. All rights reserved. 
dential resources - get combined to create functional collaborative platforms for investigation and problem solving, as well as precise descriptions of what is gained from these combinations. Discussions have identified the need for researchers to integrate values, goals, methods, and so on, in order to collaborate but with few concrete guidelines or case studies of how this can happen conceptually and methodologically.

We have here an opportunity for philosophers to actually contribute their expertise on the conceptual and methodological side of scientific processes, to formulate more informed policy criteria on how to construct effective interdisciplinary collaborations. While the philosophical literature studying the explanatory affordances of different types of conceptual and methodological integration is starting to grow (see below), there are yet few philosophical investigations exploring how effective a strategy of integration might be in creating functional collaborative problem-solving platforms given the constraints and difficulties of interdisciplinary research. Our goal in this article is to demonstrate that conceptual frameworks developed in order to integrate background models and model-building practices can be structured in ways that facilitate collaborative responses to problems. Such frameworks can thus be measured and analyzed according to their ability to facilitate effective and gainful collaborative responses.

We identify and examine one such relatively clear conceptual framework for integrating ecological and economic models developed through successful collaborative interactions between groups of resource economists and ecologists. Their interdisciplinary interaction relies on what we call a coupledmodel framework. After a brief introduction to current interdisciplinary studies (sec. 2) and integration in economics and ecology (sec. 3), we show how various features of this framework serve to demarcate the nature and structure of the collaboration required between ecologists and economists (sec. 4). Using this case, we apply two informal measures for assessing the degree to which this conceptual framework generates effective collaboration in practice, by assessing (1) the features of the framework that facilitate efficient collaborative interaction in practice given the various constraints of working across disciplinary boundaries (collaborative affordances) and (2) the gain these approaches afford through the agency of collaboration in comparison with what could be achieved working purely with one's disciplinary resources and skills (collaborative gain; sec. 5). From this information we draw several lessons on both the affordances of this kind of methodological setup for interdisciplinary research in ecology and economics and interdisciplinarity more broadly (sec. 6). We conclude by summarizing our arguments (sec. 7).

\section{Background: Interdisciplinarity from Science Policy and Philosophy of Science Perspectives. While there has been an enormous amount of re-}


search studying how to formulate good science policy for interdisciplinary research, much research is at the level of trying to conceptually distinguish interdisciplinarity from multi-, trans-, cross-disciplinarity, and so on (see Klein 2010). We restrict ourselves to the type of interactions between disciplines that much of science policy has targeted as necessary for resolving modern day complex societal and medical challenges like climate change and systemic disease. These are collaborative interactions. Insofar as any particular problem or class of problems lies outside the capacities of one particular discipline, researchers must combine and coordinate their expertise. Concepts of "integration" in science policy discussion are often closely associated with collaboration in this respect. Close interactions among researchers are seen as necessary to solve these complex problems insofar as they enable the production novel methods, practices, and conceptual frameworks derived from background fields. At this point, however, any belief that integration of this order is really necessary for successful interdisciplinary or collaborative problem solving is mainly a supposition. Indeed this article will illustrate a case of "successful" or gainful collaborative problem solving that involves little of this kind of integration (see Grüne-Yanoff and Mäki 2014).

As such, while it is plausible to think that interdisciplinary collaboration can be desirable or productive or even necessary for resolving certain sets of problems, there is still little investigation in science policy of what the specific affordances of interdisciplinary collaboration might be or of what features of an interdisciplinary research practice count as productive interdisciplinary interaction. Contemporary science policy research on interdisciplinarity has been unable to address these questions because of its narrow focus on the social and institutional factors that promote or hinder effective interdisciplinary research (cf. EURAB 2004; NAS 2004; NSF 2008).

However, the concentration of research on just these features gives the impression that if the institutional and social parameters of research are set right interdisciplinary collaboration should follow, and novel problemsolving strategies will emerge. But that can only be half the story. Researchers within a given discipline or research tradition are cognitively and practically constrained by their existing methods and practices, the skills that enable them to define and solve problems within the discipline (Marcovich and Shinn 2011). Interdisciplinary collaborations pose the great challenge for participants of having to jointly coordinate and modify their disciplinary methods and practices with those of another discipline in order to solve specific problems. This requires at least to some extent grasping another's unfamiliar techniques and practices and coming to agreement on the epistemic standards to apply to new cases, without the shared language and education of a common disciplinary background. Disciplines often diverge substantially over the epistemic values or virtues that should inform 
the selection of methodology and assess the reliability and value of its solutions (see sec. 5). Collectively this lack of shared concepts and language, educational background, and shared standards forms particular cognitive barriers that any collaborative interdisciplinary strategy must deal with in an effective and justifiable way for the participants involved. These operate in addition to those of an institutional nature, such as the lower reward of publishing outside one's discipline.

The current normative framework of interdisciplinarity in science policy glosses over these disciplinary constraints by defining interdisciplinary research as some form of "knowledge integration" that is expected "to advance fundamental understanding or to solve problems whose solutions are beyond the scope of a single discipline or area of research" (NAS 2004, 2). However, these goals are unlikely to be facilitated by refining this framework in the abstract (e.g., Holbrook 2013) or with aggregate data on research projects (Huutoniemi et al. 2010) because the above-mentioned difficulties of actual interdisciplinary interactions cannot be explored at these levels. Therefore more "internalist" and fine-grained philosophical work is required.

Philosophers of science have a history of studying the conceptual and methodological interrelations between fields and disciplines and drawing general conclusions about the nature of such relationships, how they might serve various epistemic goals they are constructed for, and what implications such relationships might have for traditional philosophical issues like reductionism, pluralism, and incommensurability (Holbrook 2013; Longino 2013). Darden and Maull (1977) in a well-cited article, for instance, analyze the conceptual and methodological structure of what they call "interfield theories," fields that combine to solve a particular set of problems that cannot be addressed by one field alone. They argue that the relations in such cases between fields cannot be understood simply as a form of reduction. Mitchell (2002) also advocates strongly for the necessity of multiple models, explanations, and theories in order to unpack complex biological phenomena. Integration of different partial and possibly inconsistent models is required in order to explain these phenomena. Mitchell argues against both promiscuous pluralism and strong unification for a more critical position that elucidates the circumstances under which one or the other is required. Winsberg (2006) uses a complex case of combining models based on different inconsistent theories from different fields operating at different scales in nanoscience to challenge intuitions that intertheoretic relationships employed by these strategies are logically derived from mereological relationships or from consistent sets of laws. The algorithmic processes exchange information between models in ways that work around these inconsistencies. He calls this "handshaking." Handshaking might be considered a complex form of model coupling (see below). His point is that these algorithms do not produce deriva- 
tions from theories or any conceivable representation of interlevel phenomena. Model use at the boundaries between fields can look very different from the ways it is typically understood in philosophy of science.

Others have taken a locally focused approach to describing particular cases of conceptual and methodological integration between specific fields and understanding how these can function to provide better explanations whether in the case of cancer research (Plutynski 2013) or evolutionary biology (Brigandt 2010; Brigandt and Love 2012; Love and Lugar 2013). Philosophers are beginning to identify general patterns or types of integration in specific fields (Leonelli 2013) and even why integration might conceptually or methodologically fail (O'Malley 2013). The kinds of integration studied may occur through interactions between researchers among different fields or through model exchange (e.g., Ross 2005; Grüne-Yanoff 2011; special issue in Perspectives on Science 21, no. 2 [2013]). Or they may simply be advocated as normatively desirable whether they are happening or not to any significant degree.

As such, most of these discussions have been narrowly focused on conceptual issues and their relevance to ongoing philosophical debates, and few of the current discussions on integration raise "interdisciplinarity" or collaboration as a specific subject or problem, despite its predominance as an issue in the science policy literature. Of course many of these discussions address interactions that take place within "disciplines" as traditionally construed, so the relevance of these discussions for interdisciplinarity is not always apparent. Interdisciplinarity, however, is the institutional and cognitive context in which many problems of integration arise, problems that in practice create challenges and obstacles researchers need to overcome on a daily basis. Our concern is not just which patterns of integration may solve explanatory problems but also how certain patterns help overcome these communication, cognitive, and other barriers that inhibit collaborative interdisciplinary problem solving.

Indeed some philosophers have begun to explore the particular social epistemological and cognitive dimensions and constraints on the practice of interdisciplinary interactions (Mattila 2005; Nersessian 2006; Andersen 2010; Rice and Smart 2011; Andersen and Wagenknecht 2013) and to map out what cognitive features of laboratory problem-solving systems and specific social interactions and exchanges help coordinate background expertise or inhibit it. All these philosophers, as well as sociologists Marcovich and Shinn (2011), recognize the importance to interdisciplinarity of researchers being able to coordinate and link models across disciplinary boundaries. Linking models provides means of linking cognitive, material, and epistemic practices so as to create effective units of group or social organization that can facilitate exchange and interaction.

Our approach follows these but is fine grained. We want to illustrate the specific roles that models (model coupling) can play in the facilitation of 
interdisciplinary collaboration in this regard and what these roles tell us about the conditions or criteria for successful practices of interdisciplinary research. Our focus in this article will thus be on conceptual frameworks collaborators build in order to combine and coordinate models from different disciplinary backgrounds. Where they arise, these frameworks are composed of sets of models or model components collected from different disciplines and sets of conceptual relations and constraints researchers formulate to integrate these different models. We analyze how these frameworks might be designed or structured so as to handle (or fail to handle) the difficulties of interdisciplinary collaboration and at the same time reliably produce some kind of explanatory or other problem-solving gain through combining expertise. These investigations promise us some guidance on what features of such frameworks predispose effective collaboration and which do not.

At the same time, our intention here is to illustrate the benefits of this kind of investigation, and how it might work, by extracting lessons in the first place from a successful case of collaboration we are currently studying. This is a case of interdisciplinary collaboration between economics and ecology, which worked effectively through a framework for combining models we call model coupling. Below we investigate the motivation and background for interdisciplinary collaboration in ecology and economics, before subsequently examining the nature and structure of this particular approach.

3. Integrating Economics and Ecology. Like many interdisciplinary collaborations, that between economics and ecology is widely encouraged in the modern context (Polasky and Segerson 2009, 410; Millennium Ecosystem Assessment 2005). However, several conceptual and normative issues have prevented productive collaborations between these two disciplines. One such issue concerns the valuation of ecological systems, highlighted by a relatively new research program called ecological economics. ${ }^{1}$ This program labels itself a transdisciplinary movement that criticizes the conventional disciplinary division between economics and ecology and promotes a new conceptual framework and analytic tools to study and solve problems of the sustainability of the global economic-ecological system (Costanza et al. 2002). ${ }^{2}$ Using this framework, Costanza et al. (1997) develop a novel but controversial estimation of monetary values of ecosystem services, that is, the total flow of services provided by the natural

1. The term ecological economics is also sometimes used to denote mainstream economics that deals with ecological issues. For example, Ecological Economics is a top journal in environmental and resource economics.

2. It should be noted that in science policy transdisciplinarity usually refers to problemsolving practices that integrate knowledge and skills from nonacademic stakeholders, not to practices that simply aim to work outside established disciplinary boundaries. 
world. Mainstream economists' reactions to this approach have been mostly negative because of its apparently economically absurd results, such as the total valuation of the ecosystem services exceeding the sum of the GDPs in the entire world. Costanza's framework is mostly perceived to be ecological in character and even as an attempt by ecology to imperialize the territory of economics. Moreover, even conservation biologists and ecologists have raised deep conceptual, methodological, and ethical problems concerning the idea of monetizing ecosystem services (Norton and Noonan 2007). Rather than philosophically analyzing and evaluating ecological economics (see, e.g., Norton and Noonan 2007), we focus on the more traditional interdisciplinary interactions in resource economics, where ecologists and economists collaborate on model building to solve specific resource management problems. Resource economics, closely related to agricultural and environmental economics, aims to understand how economic actors use natural resources in the market economy context (descriptive studies) and how natural resources should be used given various economic objectives (normative studies). Although resource economics thus characterized is a proper subfield of economics, it has traditionally been taught and researched in separate departments in many countries, partly because of its historical importance to national economies. ${ }^{3}$ It is plausible that this institutional setting, namely, resource economists' close affiliation with neighboring disciplines such as forestry, agriculture, and ecology, provides favorable conditions for their interdisciplinary collaboration. However, resource economics is a type of mainstream disciplinary economics as characterized above, and therefore a satisfactory account of its collaborations with the neighboring disciplines needs to pay closer attention to not just institutional but also its methodological conditions.

Our main example here is forest economics, a particular type of the economics of renewable resources that mainly studies forests as biological resources (other renewable resources include fish, game, etc.). The origin of forest economics goes back to the German forester Martin Faustmann, who perhaps first introduced a mathematically specific model for measuring the economic value of a piece of forest land in 1849. The modern seminal work is Samuelson (1976), which investigates the Faustmann model and shows that many famous economists have failed to specify the correct economic model for optimizing the tree growth period. ${ }^{4}$ At the same time, Samuelson criticizes the widespread resource management practice of aiming at the so-called

3. In the United States and Canada, for example, agricultural and related applied economics are mostly located in agriculture-related units, departments, faculties, or schools.

4. For the historical background of Samuelson (1976), see the special issue in Journal of Natural Resources Policy Research 4, no. 3 (2012). 
maximum sustainable yield (MSY) - the largest harvest that can be removed from the population on a regular and repeated basis. This is because, simply put, maximizing physical yields is almost always economically suboptimal given opportunity costs such as interest rates (an analogous discussion has been going on in fishery as well). The use of MSY represents something of a conventional frontline in resource management theory. Ecologists themselves criticize the use in resource management of highly simplified biological growth models that ignore relevant aspects of population structure such as size or age classes and their differential rates of growth, survival, and reproduction (Begon, Townsend, and Harper 2006, 451). Some resource economists have gone beyond criticizing MSY and, in collaboration with ecologists, started to tackle this limitation by incorporating more biologically and ecologically realistic models into their Faustmann-optimization models. Our case is an instance of such collaborations, one between a resource economics lab (the Tahvonen lab) and ecologists in Finland. ${ }^{5}$

Tahvonen (Department of Forest Science, University of Helsinki), a lab specialized in resource economics, takes an explicitly collaborative interdisciplinary approach to building optimization models for resource management. Rather than relying on relatively simple growth models from the tradition of resource management practice, it seeks to work with ecologists to build complex ecological growth models into their economic optimization models. Growth models are chosen and developed that can track the structure of tree features. These features are represented by their own variables (rather than being abstracted as biomass), which in turn enables researchers to extract more detailed and relevant information to inform forest management practice and the maximization of land value. These structural models can also incorporate environmental externalities such as carbon release/sequestration and loss/gain of biodiversity, in calculating optimal harvesting strategies. The model building is a mutual process of developing ecological models that fit the needs of economics and using the economic optimization processes to revise the ecological models (see below).

The ecologists we have interviewed view the Tahvonen lab as a very successful case of interdisciplinary collaboration between economists and ecologists, whether these individuals have participated in these collaborations or not. Publications have been produced introducing complex processbased ecological models in economic calculations (e.g., Hyytiäinen et al. 2004; Niinimäki et al. 2012; see case below). The work has been used to update forestry management policy in Finland to consider more complex harvesting strategies including uneven-aged and mixed species growth and harvesting strategies that mix tree ages and species in any stand (minimum

5. This is part of our ongoing project studying interdisciplinary interactions between ecologists and economists, comparing different projects among different groups. 
operational unit in forestry). These more complex configurations allow more efficient use of tree species (like species with different light requirements) and the preservation of forest habitats through selective thinnings (as opposed to traditional clear-cutting techniques, which are generally seen by the public as reducing the recreational value of forests). The Tahvonen lab is in fact foremost in articulating a platform for integrating economic and ecological models that can serve as a model of interdisciplinarity for many interactions between the two disciplines. Our goal so far has been to attempt to articulate the basis of its success, in a context in which the two disciplines have often struggled to interact. One reason these interactions have worked well is that the particular conceptual framework the Tahvonen lab has constructed with its collaborators affords efficient collaborative model-building efforts. We label this framework a coupled-model framework.

4. A Model-Coupling Strategy: The Tahvonen Lab. The key feature of this framework is a formal (mathematical) but largely modular coupling between abstract economic models of optimization and ecological models of population growth. This mathematical coupling in turn prescribes a particular framework for interaction between the ecologists and economists. To understand how it operates, we first have to understand the nature of this coupling, particularly how it draws on and employs the background methodological structure of both disciplines.

Ecology and economics have long shared and exchanged concepts and models, and many researchers agree that there is a similarity between the disciplines that should serve to facilitate closer integration. The basic structure of many models is often shared (Polasky and Segerson 2009; Tahvonen 2013). The Tahvonen case is evidence of how that can work. This coupledmodel-building framework operates essentially through a high-preservation strategy that largely preserves typical or traditional model-building frameworks for dealing with resource harvesting from both fields but swaps out representational components that are handled in a more sophisticated way by the other field. This it can do by drawing on the overall similarity and the relative modularity of components of such similar frameworks where they occur. Tahvonen (2013) represents the situation in figure 1, using fish harvesting as an example.

As figure 1 illustrates, both economics and ecology have particular canonical model-building frameworks for capturing the effects of harvesting on a natural resource or population. The aims of the models may be different. In economics, the aim is deriving strategies that represent rational human behavior for intervening on a dynamic population. In the ecology case, the issue is modeling population dynamics given human and other impositions on the population. In either case, though, there is a shared interest in accurate representations of both rational or optimal human behav- 
Economics of fisheries

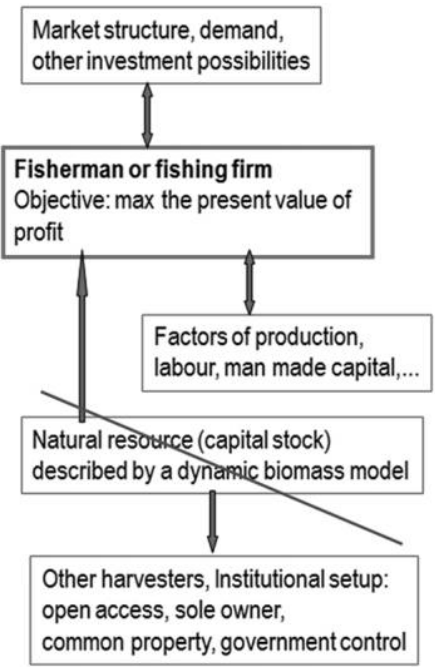

Ecology: dynamic pool fishery model

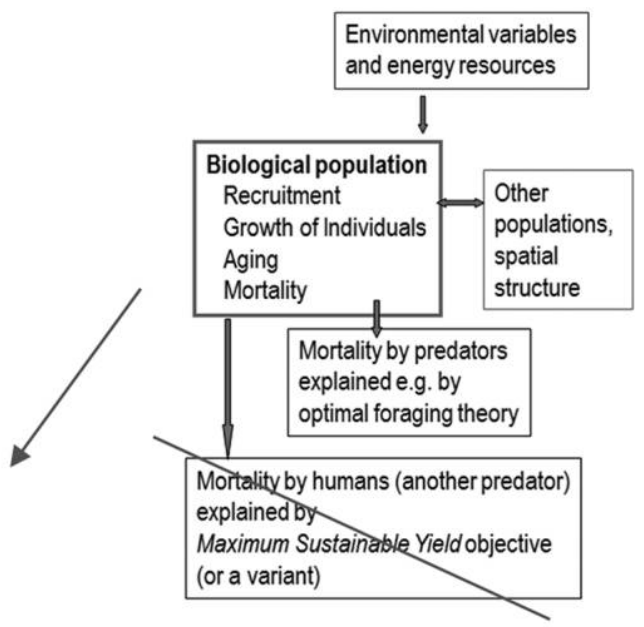

Figure 1. Harvesting of biological renewable resources (from Tahvonen 2013). We have added the diagonal slashes and arrow. Color version available as an online enhancement.

ior and population dynamics. However, for the most part each field has singled out rather different variables for modeling and different dynamic processes. The economic framework, for instance, takes into account a range of economic variables including demand and market structure and factors of production, as well as regulatory and ownership structures. But growth of the resource, in this case fish, is handled by relatively simple dynamic biomass models, which make growth a function of the total biomass at any one time (using, e.g., the Verhulst logistic growth function). These models generally make strong simplifying assumptions about the biological and ecological complexity of a fishery, and to be accurate they require good quality data and extensive parameter fitting. Nonetheless they are easy to produce and use if the data are available and require no collaboration. Ecologists have had richer models of fish ecology building in various ecological and environmental variables like predator mortality and the effects of spatial structure but also a richer account of population structure such as size and age classes. Growth is made dependent on these population features and variations rather than just biomass as a whole. However, ecologists' understanding of the implications of economic considerations on harvesting policy — such as ownership related incentives and opportunity cost of capital - is rather limited, which makes it difficult for them to translate their sophisticated ecological models into effective 
management policy (see, e.g., Begon et al. 2006, 458-59; Tahvonen 2014). Hence, by replacing the dynamic biomass model by the more complex ecological one, and MSY by more a sophisticated description of economics and optimization, there is greater potential for more accurate resource valuemaximizing strategies and better predictions of the behavior of rational economic agents and their effects on the environment.

The underlying modularity of growth and optimization components in both model-building frameworks is drawn on to substitute in more complex representations. Thankfully, in this context at least both ecologists and economist use similar spatiotemporal resolutions that facilitate this, that is, similar timescales and spatial units over which populations and human behavior are studied (cf. Battaglia and Sands 1998). Hence, much of the model structure both groups are used to using can be preserved.

In forest economics, for example, the model coupling takes place in the equation below. Economic optimization, the first part, aims to identify $h_{t}$ (harvesting strategy including the number and timing of harvest, here simplified as the number of trees harvested at time $t$ ) that maximizes $J$, the net present value of a piece of forest land or other resource over an infinite time horizon. ${ }^{6}$

$$
\max _{\left\{h_{t}\right\}} J=\sum_{t=0}^{\infty} P \times V \times h_{t} \times b^{t} .
$$

In the case of forestry, $P$ is the net revenue from timbers (market price minus costs for each timber assortment category), $V$ is the volume of timbers (given for each assortment), and $b$ is the discount factor defined as $b=1 /(1+r)$, where $r$ is the interest rate.

While $P$ and $b$ are both economic variables, $V$ is the second volume component of the model, which measures the quantity of valuable material taken in a particular harvest on the basis of the structure of the forest population (number of age classes, number of species, etc.) and properties of individuals in that population (height, number of whorls, branches, etc.). Volume $V$ itself is subject to ecological growth functions that specify the movement of population members through different growth states and the evolution of different tree properties as a result. Mathematically, $V(t)=f\left(\boldsymbol{z}(t), h_{t}\right)$, where the set of $z$ measure the structure and features of the population. The ecological growth equations update each $z_{i}$ in $z$ as a function of the other pop-

6. This is a highly schematic representation of the functions actually used in forest economics, which has to optimize a number of variables simultaneously given the number of size classes, the number of timber assortment categories, etc. In addition, it can be made economically more realistic by incorporating factors such as the tax on capital income, stand regeneration costs, and annual administrative costs. See Tahvonen, Pihlainen, and Niinimäki (2013) as an example. 
ulation variables $\boldsymbol{z}_{i, t+1}=f_{i}\left(\boldsymbol{z}_{1, t}, \boldsymbol{z}_{2, t} \ldots\right)$. The forest structure can be empirically estimated, and the growth function can for the most part be constructed, at least initially, independently of harvesting interruptions by using data from wild growth conditions. Such functions gain plausibility from how well they model available natural regeneration data.

In Tahvonen's lab the framework described in figure 1 is applied in forestry, fisheries, and reindeer husbandry, suggesting that it is quite general. In all these fields the studies are done together with ecologists and economists. For forestry modeling in the lab, economists have collaborated with mathematical ecologists (specifically the Mäkelä lab) at the University of Helsinki who have been building complex process-based models. These models are more complex than the majority of models in forest management that have usually employed empirical statistical models of growth. Processbased models in contrast try to model causal processes (including feedback from silvicultural practices) underlying tree growth at detailed levels of bole, branches, roots, and foliage. This enables in general greater robustness of model predictions outside the range of data used to build the models and over longer timescales, which is a factor important in economic analysis. One simulation model platform of importance for the Tahvonen lab is PipeQual, built by the Mäkelä group (Mäkelä et al. 2000; Mäkelä and Mäkinen 2003). This computational model builds in the competitive effects of tree-to-tree interactions (such as shading and space requirements) and the distribution of growth among different parts of tree structure into growth dynamics. Importantly for economic analysis, PipeQual has been constructed by ecologists to track variables relevant to wood quality and value like whorl and branch distribution and size.

This combination of economic optimization and ecological growth models instituted through this general schema gives rise to what can usefully be described as a coupled-model framework for model building. By coupledmodel framework we are referring to a model-building framework formed when two or more established models or classes of models are mathematically or otherwise combined such that information calculated or generated by one model is used as input to another to form an overall model-based solution to particular problems. Such a framework preserves for the most part the structure of those models. The models are in this sense coupled rather than say more generally "integrated" to the extent that the model structures are not significantly transformed or altered in order to combine them. The relations that may achieve this coupling may well be complex, as in the case of Winsberg's handshaking algorithms using finite element mesh methods, but the component models still operate independently on the information they are provided.

Coupling models in this way from different disciplines or fields will generate constraints on model-building practices and coordinate the model- 
building activities of either group. These coordinated tasks and practices will comprise an interdisciplinary model-building framework. The central advantages of such frameworks lie in the clarity of the (mathematical) relationships and the degree to which this helps define clear collaborative relationships between participants and maintains the established modelbuilding practices and standards of the participants themselves.

In the ecological-economics schema we have discussed above, the mathematical nature of the coupling is very clear. Ecological variables provide input for the economic variables encoded in the objective function through the volume function that transforms the state of a population given a harvesting strategy into an economic quantity $V(t)=f\left(z(t), h_{t}\right)$. In the case of forestry modeling in the Tahvonen lab, the volume function is constructed to record the quantity of valuable timber from many different tree properties and then incorporated within the objective function. The ecological model is designed to simulate that information over time. The volume function is thus coupled to the ecological growth equations, using input from them to calculate the effect of a given harvest strategy. During optimization the ecological model is allowed to run, and the objective function is calculated for different harvest strategies. An optimal strategy maximizes the economic value of a piece of forest land (cf. Faustmann 1849), summing up all the future streams of revenue discounted by a given interest rate.

This mathematical coupling when applied to specific problems results in particular constraints on the model-building process itself. These constraints serve to focus the issues of collaboration on a specific set and thus help to set the bounds of the collaborative relationship in a clear fashion between ecologists and economists in the model-building process. For example, the economic optimization sets constraints on the precision and accuracy of the ecological model. The model must be adjusted in resolution (of, e.g., timescale) to fit economic timescale, and it must be accurate enough for the long-term cycles over which optimization operates. Ecologists in these cases have to select and adjust models to fit these requirements (and economists have to select collaborative partners who build or are willing to provide these kinds of models and modify them). The accuracy requirement is particularly important and the central reason for the choice of process-based models. Process models are generally thought to work more reliably outside the data sets used to build them. In theory, an optimization algorithm could thus explore a model without risk of ending up with a solution outside a model's range of validity. Mäkelä et al. (2000) discuss in detail how process-based ecological models, such as PipeQual, are adaptable for practical implementation. At the same time, the coupling of detailed process-based ecological models requires economists to develop and adapt new mathematical methods to solve the optimization problems. As such the model-coupling framework applies constraints to the models and practices 
of both groups, which serves to structure and constrain their interaction. In both cases, however, meeting these constraints is achieved squarely within the range of the expertise of each party.

Coupling these ecological models with an economic optimization process couples in further ways the tasks of the various model builders. Optimization is very good at discovering any weak points in the ecological processbased model, since it will, in the course of calculating an optimum, search a vast range of possibilities and pick out solutions with empirically unrealistic harvesting strategies (e.g., too dense forests that have never been seen in Finland). Optimal solutions that look unrealistic signal problems with the ecological process-based model because such a model should be able to depict realistic forest states outside the range of its empirical validation. In at least three collaborations we followed, this was an important dimension of the process by which the model building operated, leading to the improvement of the underlying ecological model. The model-building process thus cycles information back and forth by virtue of the way ecological models are incorporated in the optimization process. But apart from these accommodations and feedback relationships the model-building practice of each group is largely preserved with respect to the kind of models they build and how they justify them. The standard of what counts as a good ecological model is determined by the ecologists and remains within their expertise. Likewise, the economic legitimacy of an optimal solution remains within the expertise of the economists.

Finally, the relatively clear and straightforward nature of this framework provides a platform for building more complex collaborative models that can take into account other variables either group sees as significant. For instance, one researcher we studied, Sampo Pihlainen, was able to do just this. Pihlainen's first published article (Tahvonen et al. 2013) studied optimization of timber production in boreal Scots pine stands using PipeQual. Since the problem cannot be analytically solved, Pihlainen developed derivate-free optimization algorithms, using generalized pattern search by Matlab. He pointed out four benefits of coupling a Faustmann model with a detailed process-based ecological model for building more complex accounts. First, it enabled simultaneous optimization of all management actions without ad hoc constraints on, for example, thinnings (intermediate harvests). This resulted in new findings, for example, that thinnings may provide as much as $40 \%$ of the overall revenue for Scots pine. Second, it enabled optimal solutions with timber quality considerations. This resulted in new findings, for example, that initial density and number of thinnings depend on site conditions and interest rates and that doubling the price of the superior A grade saw timber may lengthen the optimal rotation period, contrary to what the previous studies using empirical-statistical ecological models suggested. Third, the process-based model enabled him to study 
carbon storage in various parts of trees and by-products and its implications for the efficiency of bioenergy use given different $\mathrm{CO}_{2}$ subsidy schemes (Pihlainen, Tahvonen, and Niinimäki 2014). The process-based model made it possible to estimate carbon released from timber products, enabling Pihlainen to compare a gross subsidy system with a net subsidy system. He also obtained a new result showing that the optimal carbon storage strategy (e.g., lengthening rotation or modifying thinnings) depends on tree species (e.g., Norway spruce or Scots pine). Fourth, the process-based model enabled Pihlainen to begin to model the impact of climate change on optimal stand management (Pihlainen and Tahvonen 2014).

The Pihlainen case illustrates two important points: first, environmental externalities (such as the cost/benefit of $\mathrm{CO}_{2}$ release/storage) can be incorporated into the economic optimization model, not only in principle as Samuelson (1976) noted but also in practice. We cite this as a benefit of studying in detail bottom-up interdisciplinary collaborations such as these, rather than focusing on controversies about the necessity of paradigm shifts in economics. Second, this environmentally sensitive approach is afforded by coupling a detailed ecological model with an essentially good old Faustmann optimization model. The increase of complexity requires modern computational power, but the structure of coupling remains relatively simple and clear, and this affords further incremental interdisciplinary development of model scope. In the next section, we try to generalize these lessons above.

\section{The Collaborative Affordances and Collaborative Gain of the Coupled-}

Model Framework. It is clear then that this framework plays a very important role in setting and determining the nature and structure of the collaborative interactions between ecologists and economists in solving these resource management problems. We suggest in fact two dimensions along which one can unpack the effectiveness of a conceptual framework for collaborative model building and then apply them in this case.

First, we can explore the collaborative gain of a framework, by measuring the degrees and dimensions by which these strategies achieve more in terms of the epistemic virtues important in a particular case through collaboration, such as predictive power or explanatory scope and reliability, than could be achieved by each discipline working alone with its own methods and practices. ${ }^{7}$ Measuring this gain should take into account the

7. Fallis (2006) rightly points out that the notion of epistemic gain ("epistemic value" in his terms) should take into account opportunity costs of collaborating with other researchers when the researchers could have pursued noncollaborative research independently. We do not make such an explicit epistemic cost-benefit analysis here (cf. epistemic value theory; Thagard 1997; Wray 2002), although we think it is clear in this case that the benefits of collaboration outweigh any epistemic costs. 
extent to which these strategies are consistent with, and improve on, the disciplinary aims and objectives of the participants (e.g., environmental concerns such as carbon storage, as well as economic concerns such as efficiency).

Second, we can explore the collaborative affordances of a conceptual framework, meaning the features of the framework that facilitate collaboration, or more precisely facilitate the ability of collaborators to define tasks and coordinate them in order to emulate efficient processes of model building and model validation for a particular problem. Such affordances help overcome the various constraints of trying to do science across disciplinary boundaries. Efficient processes of model building require, for instance, the ability of collaborators to be able to collect and combine evidence and data appropriate for building and validating models built within the framework. It requires collaborators to be able to build and adjust the models required or imagined. It requires basic agreement on standards of validation. The ability of collaborators to do these things obviously has some relationship to what they know how to do, given background methods and practices. A framework with few collaborative affordances provides little structure that helps researchers define their tasks and coordinate them in order to generate efficient model-building processes.

The notion of collaborative affordances, however, should not be taken here as precisely defined. We introduce it rather to shift our attention to different kinds of questions that can be asked of model building in interdisciplinary contexts. When we study the affordances of a framework, we are ultimately trying to assess how easy it will be, given the structure of that framework, for collaborators to implement it so as to produce good results. In general, frameworks that lack collaborative affordances are less likely to yield the collaborative gains they strive for.

Turning to our case, in terms of collaborative gain the coupled-model framework provides a platform for linking more complex specialized models together from either field and thus producing a more complex overall model that could not be produced within either field, given the disciplinary expertise required for each part. The framework allows economists access to specialized model-building knowledge and practices in ecology beyond their expertise and competence that can be fit to a standard optimization framework in economics. Thus they get more complex representations of ecological growth processes with which to give more accurate predictions of what strategies best maximize economic outcomes. Ecologists get the opportunity to contribute their ecological knowledge and skills to a more sophisticated platform for maximizing profit and policy decision making. Certainly given the role economists play in policy making (compared with ecologists) this is no small thing. It is a chance for ecologists to have more ecologically informed models count in policy settings such as forest management. As such, 
the framework provides a platform for combining specialized knowledge and expertise to produce a result beyond the competence of either group alone and certainly beyond what has been traditionally produced by both groups.

Of course many collaborative projects aim to leverage the expertise of the participants to produce a result they could not achieve alone. A coupledmodel-building framework in the manner described above, however, has distinct collaborative affordances for achieving interdisciplinary collaboration. Most important, the framework provides a relatively clear division of labor and distribution of tasks between the groups that preserves to a large extent their familiar model-building practices. This ensures that tasks allocated remain firmly within their expertise. Having a framework like this in place that relies on preexisting models and processes of modeling cuts down the need to produce and agree on novel model-building frameworks and novel concepts - often considered a hallmark of interdisciplinary collaborative research - that require novel practices. The framework obviates the need for any new models or concepts to handle the specific problemsolving tasks. It works efficiently with what is already to a large extent available and within the capacity of both groups to produce. Economists, for instance, as experts on optimization algorithms can concentrate on applying and developing those, while deferring the question of how best to model the particular ecological phenomena, and what methods to use to do so, to the ecologists.

One issue commonly requiring interaction in collaborative interdisciplinary work is reaching agreement over the epistemic standards to apply to the models and data involved (Andersen and Wagenknecht 2013). In this respect, the framework we have described above allows the preservation for the most part of the epistemic standards of either group for assessing the validity of their contributions, reducing the need for interaction over issues of evidence and validity. Agreeing on epistemic standards is often a major source of contention between different groups, which can compromise interdisciplinary projects. For instance, in systems biology, a collaborative field involving molecular biologists and engineers, there can be considerable disagreement over the ability of mathematical averaging and approximation techniques to find robust relationships independently of data error (MacLeod and Nersessian 2014).The field has itself yet to reach an accommodation on these complex issues. They are ultimately disputes over the epistemic standards required to trust models produced.

The framework we have described above more or less alleviates or avoids the need for this by keeping model-building and evidential tasks for each group largely within the scope of each group. Some accommodation is required to produce ecological models suitable for economic requirements, but the validity of those models remains for the most part an issue for the 
ecologists. The various collaborative affordances of this coupled framework can be summarized as follows. The framework,

1. Provides clear division of labor within the expertise of both groups, relatively clear roles for each group, built around limited/structured interactions between the two groups, allowing both to mainly concentrate on what they are trained for.

2. Allows straightforward coupling: does not require new models, mechanisms, or concepts but can generate new results.

3. Provides corrective feedback to ecological models.

Additionally this modeling framework provides pathways for scaling up model complexity while nonetheless preserving its basic structure. For example, if other resource features or properties are to figure in a valuation, this can be done by adding new variables in the economic model and new structure in the ecological model that will measure them at each time step. The result may require a commensurate increase in computational power to handle the optimization algorithm or more powerful algorithmic techniques but will not require any new fundamental change in the model-building framework. And yet this conservative framework can yield in terms of gain results radically different from those obtained by more conventional optimization models. By applying these complex ecological models, the framework has refuted some long-accepted results from more simplistic models in economics such as that clear-cuts are necessary for economically profitable forestry. As such, a model produced using this framework can be used as a basis to collaborate on expanding models to incorporate new variables that build in, for instance, more externalities and management interventions, as we saw. This kind of move is often high on the agenda of ecologists who desire more environmental considerations be taken into account-or priced into-economic calculations. In the words of Marcovich and Shinn (2011), this framework creates a "borderland" between disciplines that allows both disciplines to exploit potential elasticities in their methodological practice and conceptual frameworks, providing both in turn space for their own disciplinary innovation.

6. General Lessons for Effective Interdisciplinarity. What we have described above are the various features of this coupled-model framework we think make it conducive to interdisciplinary collaborations between ecology and economics. There are a lot of obvious contingencies that might seem to prevent us from drawing too many conclusions from this case about conditions more generally for effective interdisciplinary research. But some of the insights we have drawn would seem to have general relevance to 
assessing the strength and likelihood of successful collaboration of any particular collaborative strategy for combining methods, practices, and researchers from different disciplines.

For instance, on the basis of our case study above it would seem that any conceptual or methodological strategy for combining background methods and practices is more likely to succeed in producing a gainful collaborative response to a problem if it,

1. Combines models outside the range of expertise of the other group that,

2. Provide a very clear structure for interactions that limits and sequentially organizes tasks and keeps them firmly within the expertise of participants and,

3. Advances the disciplinary aims of each group.

A coupled-model-building framework of the type described above does provide a framework that seems to instantiate these objectives in the context of ecology and economics. The third condition ensures that motivations and incentives to engage in the research are well aligned with the research itself. In this case, for instance, the disciplinary aims of ecology include the interest in having a framework that can factor in the environmental costs of resource harvesting and that allows ecology to have a voice in policy contexts. If all hold, then a research assessor might raise his or her expectation that such a project will result in collaborative gain.

These are not meant to serve as strict conditions, only as indicators. Many would consider, for instance, condition 2 a restriction on interdisciplinary research rather than a condition for it. This is where on the basis of the case we can make a more telling point, in line with Grüne-Yanoff and Mäki's (2014) argument against defining interdisciplinary success in terms of integration. The example of interdisciplinarity provided by a coupledmodel-building framework does not produce the kinds of output often seen to be the benefit of interdisciplinary collaboration, that is, new concepts, methods, and model templates leading perhaps to the generation of new interdisciplines. Thoroughly new ways of thinking about a class of problems will not necessarily emerge from such a framework. In fact it seems clear that the case we have described here is largely productive because it tries to preserve disciplinary methods, concepts, and practices. Its stability and effectiveness consists in doing so. It must be reiterated even so that this does not mean there is no effective gain from collaboration here, because it is clear that the models and calculations produced through this framework are more complex and richer than what could otherwise be gained by either group working alone. Our case serves as a model for more conservative but well-grounded interdisciplinary research. Given the general complexity of 
the phenomena much interdisciplinary research is trying to tackle and the genuine difficulties of collaborating with researchers from different backgrounds, it seems an important baseline possibility.

7. Conclusion. Our aim here has been to show how various features of how models are put together for an interdisciplinary collaboration have implications for how effective a collaboration will be in achieving its problemsolving goals. We have posed two distinct dimensions along which one can explore the effectiveness of a conceptual framework for combining and coordinating background models - collaborative affordances and collaborative gain - and shown how the use of a coupled-model framework to coordinate and combine background models from ecology and economics provides a large degree of both. We have also drawn from this particular case some general features that would appear important for any particular strategy of combining methods and practices from different disciplinary backgrounds that help overcome the constraints of working across boundaries.

The result we hope is at least the starting point for more philosophical engagement with the ways in which strategies of integration afford or constrain genuine collaborative approaches to particular problems. This will take philosophy of science deeper in its investigation of interdisciplinarity. Given the importance in policy settings of encouraging and promoting interdisciplinary collaboration, we have an opportunity for philosophy to actually contribute its expertise on the conceptual and methodological side of scientific processes to formulating more informed policy criteria on how to construct effective interdisciplinary collaborations.

\section{REFERENCES}

Andersen, Hanne. 2010. “Joint Acceptance and Scientific Change: A Case Study.” Episteme 7:24865.

Andersen, Hanne, and Susann Wagenknecht. 2013. "Epistemic Dependence in Interdisciplinary Groups." Svnthese 190 (11):1881-98.

Battaglia, Michael, and Peter J. Sands. 1998. "Process-Based Forest Productivity Models and Their Application in Forest Management." Forest Ecology and Management 102:13-32.

Begon, Michael, Colin R. Townsend, and John L. Harper. 2006. Ecology: From Individuals to Ecosystems. Oxford: Blackwell.

Brigandt, Ingo. 2010. "Beyond Reduction and Pluralism: Toward an Epistemology of Explanatory Integration in Biology." Erkenntnis 73 (3): 295-311.

Brigandt, Ingo, and Alan Love. 2012. "Conceptualizing Evolutionary Novelty: Moving beyond Definitional Debates.” Journal of Experimental Zoology B 318:417-27.

Costanza, Robert, John Cumberland, Herman Daly, Robert Goodland, and Richard Norgaard. 2002. An Introduction to Ecological Economics. Boca Raton, FL: CRC.

Costanza, Robert, Ralph d'Arge, Rudolf de Groot, Stephen Farber, Monica Grasso, Bruce Hannon, Karin Limburg, Shahid Naeem, Robert V. O’Neill, Jose Paruelo, Robert G. Raskin, Paul Sutton, and Marjan van den Belt. 1997. "The Value of the World's Ecosystem Services and Natural Capital." Nature 387:253-60. 
Darden, Lindley, and Nancy Maull. 1977. "Interfield Theories." Philosophv of Science 44 (1): $43-$ 64.

EURAB (European Union Research Advisory Board). 2004. "Interdisciplinarity in Research." EURAB 04.009-Final, EURAB.

Fallis, Don. 2006. "The Epistemic Costs and Benefits of Collaboration." Southern Journal of Philosophy 46:197-208.

Faustmann, M. 1849. "On the Determination of the Value Which Forest Land and Immature Stands Possess for Forestry." English edition in "Martin Faustmann and the Evolution of Discounted Cash Flow," ed. M. Gane, Oxford Institute Paper 42 (1968). Original version: Martin Faustmann, "Berechnung des Wertes welchen Waldboden sowie noch nicht haubare Holzbestände für die Waldwirtschaft besitzen," Allgemeine Forst-und Jagd-Zeitung 15 (1849): 7-44.

Gibbons, Michael, Camille Limoges, Helga Nowotny, Simon Schwartzman, Peter Scott, and Martin Trow. 1994. The New Production of Knowledge: The Dynamics of Science and Research in Contemporary Societies. London: Sage.

Grüne-Yanoff, Till. 2011. "Models as Products of Interdisciplinary Exchange: Evidence from Evolutionary Game Theory." Studies in Historv and Philosophy of Science 42:386-97.

Grüne-Yanoff, Till, and Uskali Mäki. 2014. "Introduction: Interdisciplinary Model Exchanges." Studies in History and Philosophy of Science 48:52-59.

Holbrook, J. Britt. 2013. "What Is Interdisciplinary Communication? Reflections on the Very Idea of Disciplinary Integration." Svnthese 190 (11): 1865-79.

Huutoniemi, Katri, Julie Thompson Klein, Henrik Bruun, and Janne Hukkinen. 2010. “Analyzing Interdisciplinarity: Typology and Indicators." Research Policy 39 (1): 79-88.

Hyytiäinen, Kari, Pertti Hari, Tero Kokkila, Annikki Mäkelä, Olli Tahvonen, and Juhani Taipale. 2004. "Connecting a Process-Based Forest Growth Model to Stand-Level Economic Optimization." Canadian Journal of Forest Research 34 (10): 2060-73.

Klein, Julie Thompson. 2010. "A Taxonomy of Interdisciplinarity." In The Oxford Handbook of Interdisciplinarity, ed. Robert Frodeman, Julie Thompson Klein, and Carl Mitcham, 15-30. Oxford: Oxford University Press.

Leonelli, Sabina. 2013. "Integrating Data to Acquire New Knowledge: Three Modes of Integration in Plant Science." Studies in Historv and Philosophv of Science C 44 (4): 503-14.

Longino, Helen E. 2013. Studying Human Behavior: How Scientists Investigate Aggression and Sexuality. Chicago: University of Chicago Press.

Love, Alan C., and Gary L. Lugar. 2013. "Dimensions of Integration in Interdisciplinary Explanations of the Origin of Evolutionary Novelty." Studies in Historv and Philosophv of Science C 44 (4): 537-50.

MacLeod, Miles, and Nancy J. Nersessian. 2014. "Strategies for Coordinating Experimentation and Modeling in Integrative Systems Biology.” Journal of Experimental Zoologv B 322 (4): 230 39.

Mäkelä, Annikki, Joe Landsberg, Alan R. Ek, Thomas E. Burk, Michael Ter-Mikaelian, Göran I. Ågren, Chadwick D. Oliver, and Pasi Puttonen. 2000. "Process-Based Models for Forest Ecosystem Management: Current State of the Art and Challenges for Practical Implementation." Tree Phvsiology 20 (5-6): 289-98.

Mäkelä, Annikki, and Harri Mäkinen. 2003. "Generating 3D Sawlogs with a Process-Based Growth Model." Forest Ecology and Management 184 (1): 337-54.

Marcovich, Anne, and Terry Shinn. 2011. "Where Is Disciplinarity Going? Meeting on the Borderland." Social Science Information 50 (3-4): 582-606.

Mattila, Erika. 2005. "Interdisciplinarity 'In the Making': Modeling Infectious Diseases." Perspectives on Science 13 (4): 531-53.

Millennium Ecosystem Assessment. 2005. Ecosystems and Human Well-Being: General Synthesis. Washington, DC: Island.

Mitchell, Sandra D. 2002. "Integrative Pluralism." Biologv and Philosophv 17 (1): 55-70.

NAS (National Academy of Sciences). 2004. "Facilitating Interdisciplinary Research." Recommendation from the National Academy of Sciences/National Academy of Engineering/Institute of Medicine report, National Academies, Washington, DC.

Nersessian, Nancy J. 2006. "The Cognitive-Cultural Systems of the Research Laboratory." Organization Studies 27 (1): 125-45. 
Niinimäki, Sami, Olli Tahvonen, and Annikki Mäkelä. 2012. “Applying a Process-Based Model in Norway Spruce Management." Forest Ecology and Management 265:102-15.

Norton, Bryan G., and Douglas Noonan. 2007. "Ecology and Valuation: Big Changes Needed." Ecological Economics 63 (4): 664-75.

NSF (National Science Foundation). 2008. "Impact of Transformative Interdisciplinary Research and Graduate Education on Academic Institutions." Workshop report, NSF, Arlington, VA.

O’Malley, Maureen A. 2013. "When Integration Fails: Prokaryote Phylogeny and the Tree of Life." Studies in Historv and Philosophv of Science C 44 (4): 551-62.

Pihlainen, Sampo, and Olli Tahvonen. 2014. "Economics of Boreal Scots Pine Stands in Changing Climate." Unpublished manuscript, University of Helsinki.

Pihlainen, Sampo, Olli Tahvonen, and Sami Niinimäki. 2014. "The Economics of Timber and Bioenergy Production and Carbon Storage in Scots Pine Stands." Canadian Journal of Forest Research 44 (9): 1091-1102.

Plutynski, Anya. 2013. "Cancer and the Goals of Integration." Studies in Historv and Philosophy of Science C 44 (4): 466-76.

Polasky, Stephen, and Kathleen Segerson. 2009. "Integrating Ecology and Economics in the Study of Ecosystem Services: Some Lessons Learned." Annual Review of Resource Economics $1: 409-34$.

Rice, Collin, and Joshua Smart. 2011. "Interdisciplinary Modeling: A Case Study of Evolutionary Economics." Biology and Philosophy 26 (5): 655-75.

Ross, Don. 2005. Economic Theory and Cognitive Science: Microexplanation. Cambridge, MA: MIT Press.

Samuelson, Paul A. 1976. "Economics of Forestry in an Evolving Society." Economic Inquirv 14 (4): 466-92.

Tahvonen, Olli. 2013. "Economics and Ecology Are Almost Alike, but Do They Neglect One Another?" Presentation at AID - Agora for Interdisciplinary Debate, University of Helsinki, October 14.

. 2014. "Ekologian ja taloustieteen välisen yhteistyön ongelmista." Tieteessä Tapahtuu 2:44-46.

Tahvonen, Olli, Sampo Pihlainen, and Sami Niinimäki. 2013. "On the Economics of Optimal Timber Production in Boreal Scots Pine Stands." Canadian Journal of Forest Research 43 (8): 719-30.

Thagard, Paul. 1997. "Collaborative Knowledge.” Nous 31:242-61.

Winsberg, Eric. 2006. "Handshaking Your Way to the Top: Simulation at the Nanoscale." Sociology of Sciences Yearbook 25 (3): 139-51.

Wray, K. Brad. 2002. "The Epistemic Significance of Collaborative Research." Philosophy of Science 69 (1): 150-68. 